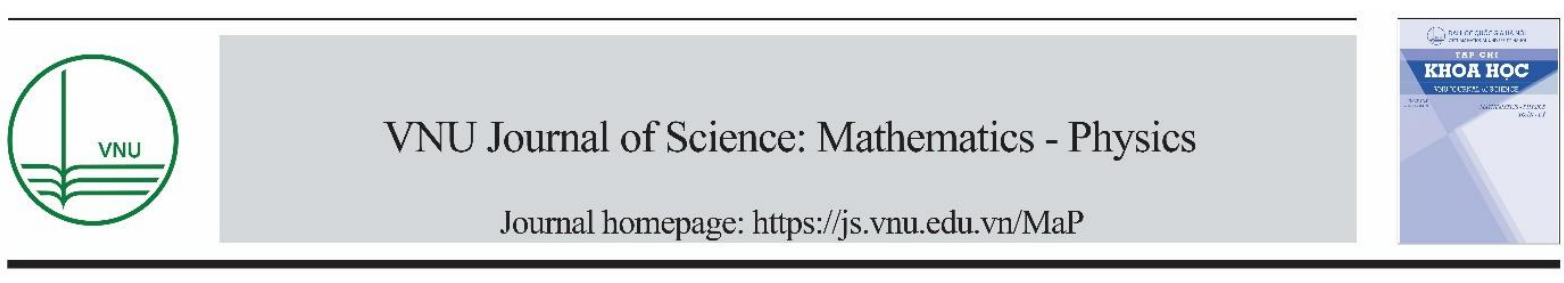

Original Article

\title{
Effect of Annealing Temperature on Photoluminescence Emission and Photocatalytic Activity of Hydrothermal $\mathrm{ZnO}$ Nanorods
}

\author{
Nguyen Xuan Sang* \\ Department of Electronics and Telecommunication, Saigon University, 273 An Duong Vuong, Ward 3, \\ District 5, Ho Chi Minh City, Vietnam \\ Received 18 November 2018 \\ Revised 08 January 2019; Accepted 20 January 2019
}

\begin{abstract}
This work reports photoluminescence evolution of hydrothermally homogeneous $\mathrm{ZnO}$ nanorods under thermal annealing at various temperatures. The crystalline structure and morphology of synthesized samples were characterized by X-ray diffractometry and Scanning Electron Microscopy. The optical properties induced by defect state transitions were investigated by photoluminescence emission. Besides defect states induced emissions in the visible range, the photocatalytic activity of annealed samples was evaluated which indicated that the higher visible photoluminescence intensity gives the better catalytic activity.
\end{abstract}

Keyword: $\mathrm{ZnO}$ nanorod, thermal treatment, photoluminescence, photocatalyst.

\section{Introduction}

With a wide bandgap $(3.37 \mathrm{eV})$ and large exciton binding energy $(60 \mathrm{meV})$ at room temperature, $\mathrm{ZnO}$ is one of the most interesting oxide semiconductors which has received huge attention from scientists worldwide in many application aspects such as ultraviolet (UV) laser, white light emitting diode (LED), photocatalyst, and sensor [1-3]. Depending on fabrication technique, many types of nano-sized $\mathrm{ZnO}$ morphology could be obtained such as nanoparticle, nanowire, micro/nanorod, microdisk. In semiconductor technology and application, one-dimensional $\mathrm{ZnO}$ nanostructure such as

\footnotetext{
${ }^{*}$ Corresponding author.

E-mail address: sangnguyen@sgu.edu.vn

https//doi.org/ 10.25073/2588-1124/vnumap.4299
} 
nanowire, nanorod is technically important due to the unipolar characteristics which could play a crucial role as interconnects in nanoscale electronic devices.

Among various synthesis means, the hydrothermal method is a cheap, safe and friendly-user technique which could easily fabricate uniform $\mathrm{ZnO}$ nanostructures. Hence, in this study, $\mathrm{ZnO}$ nano/microrods were one-pot hydrothermally synthesized, then thermal annealing treatment was carried out directly at different temperatures. Crystalline structure and morphology of fabricated samples were characterized by X-ray diffractometric (XRD) and Scanning Electron Spectroscopy (SEM). Photoluminescence (PL) emission was investigated at room temperature with an excitation wavelength of $325 \mathrm{~nm}$. The photocatalytic activity of annealed $\mathrm{ZnO}$ samples was evaluated by UV-Vis (HACH 5000) system measuring the degradation of methylene blue in solution under natural sunlight irradiation.

\section{Chemicals and fabrication process}

Zinc acetate dihydrate $\left(\mathrm{Zn}\left(\mathrm{CH}_{3} \mathrm{COO}\right)_{2} .2 \mathrm{H}_{2} \mathrm{O}, 99 \%\right.$ Merck), Sodium hydroxide ( $\mathrm{NaOH}, 99 \%$ Merck) and Hexamethylenetetramine (HMTA, Merck), bi-distilled water were purchased and/or used without further purification. The synthesis procedure was started with two solutions of $\mathrm{NaOH} 8 \mathrm{~g}$ and $\mathrm{Zn}(\mathrm{Ac})_{2} 4.39 \mathrm{~g}$ obtained in distilled water $50 \mathrm{ml}$. Then these solutions were mixed in the presence of hexamethylenetetramine (HMTA) $0.024 \mathrm{~g}$ at room temperature in $30 \mathrm{~min}$ of magnetic stirring. The clear solution was poured into a Teflon-lined autoclave and hydrothermally heated at $150^{\circ} \mathrm{C}$ for $8 \mathrm{~h}$. The autoclave was naturally cooled to room temperature (RT) and the white precipitate was washed with distilled water until $\mathrm{pH}$ reaches 7 . Then, the powder was dried at $100^{\circ} \mathrm{C}$ overnight. Finally, these samples were annealed at $400^{\circ} \mathrm{C}, 700^{\circ} \mathrm{C}$, and $900^{\circ} \mathrm{C}$ named as $\mathrm{ZnO} 400, \mathrm{ZnO} 700$ and $\mathrm{ZnO} 900$, respectively.

\section{Results and discussion}

\subsection{Structural and morphological analysis}

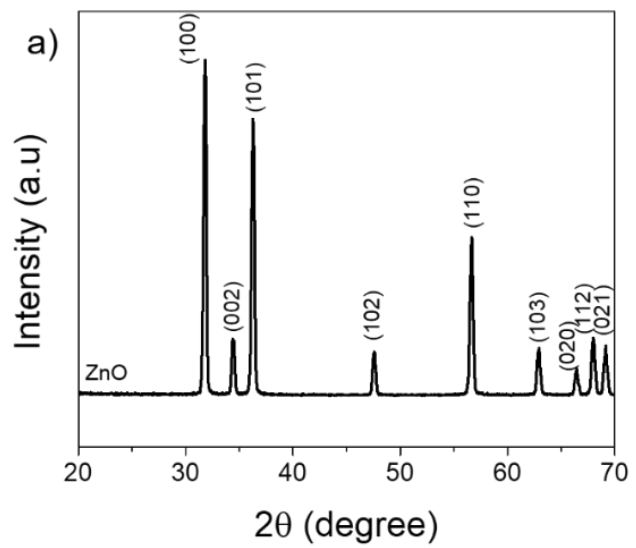

b)

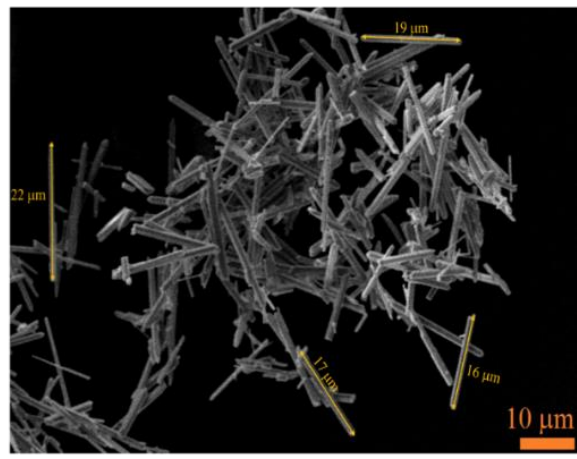

Figure 1. Structure and morphology characterizations: a) XRD patterns, b) SEM image. 
The crystal structure and morphology of the synthesized $\mathrm{ZnO}$ microstructures were carried out via X-ray diffraction (XRD) and SEM, as shown in Fig. 1a, b, respectively. The main diffraction peaks implied that produced powders were highly single-phase hexagonal wurtzite structure, with average crystal size being $27.11 \mathrm{~nm}$ and lattice constants of $a=0.3249 \mathrm{~nm}$ and $c=0.5212 \mathrm{~nm}$. This result is in the good agreement with JCPDS 36-1451 card [4]. There was no other peak of impurities observed. In addition, according to Fig. 2b, the SEM images showed that the morphology of $\mathrm{ZnO}$ was homogeneously uniform rod-like shape with length of $16.0-22.0 \mu \mathrm{m}$ and dimension ranged from 0.8 to $1.6 \mu \mathrm{m}$.

\subsection{Photoluminescence analysis}

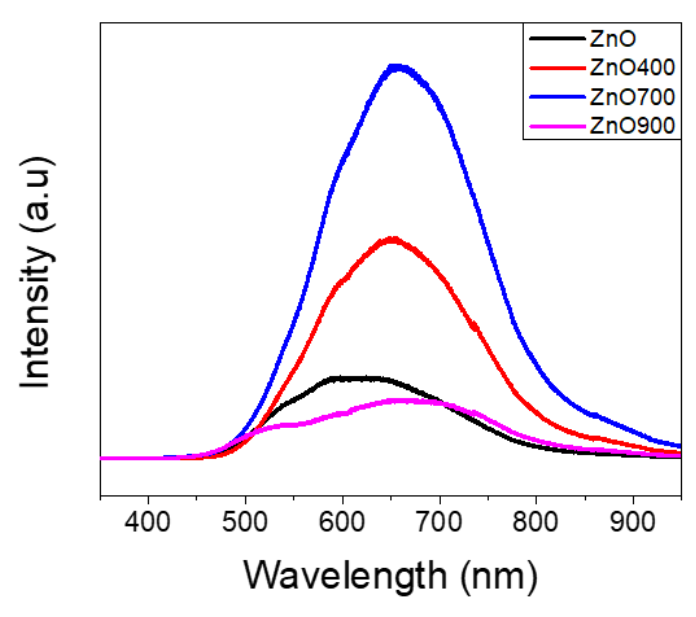

Figure 2. Room temperature photoluminescence emission of synthesized samples.

Photoluminescence is a suitable and nondestructive technique in order to determine radiative transitions in the band gap. In this study, PL measurements were performed at room temperature. In principle, the UV peak in the PL spectrum, at around $380 \mathrm{~nm}(3.26 \mathrm{eV})$ is related to the emission from the conduction band to the valence band. When as-prepared $\mathrm{ZnO}$ treated at different temperatures, $\mathrm{ZnO} 400, \mathrm{ZnO} 700$ and $\mathrm{ZnO} 900$, no UV peaks were observed in these samples. Besides the UV emission peak, visible emissions also are important as they relate to defect level transition in the material. Popular intrinsic defects in $\mathrm{ZnO}$ are zinc vacancies $\left(\mathrm{V}_{\mathrm{Zn}}\right)$, zinc interstitials $\left(\mathrm{Zn}_{\mathrm{i}}\right)$, oxygen vacancies $\left(\mathrm{V}_{\mathrm{O}}\right)$, oxygen interstitials $\left(\mathrm{O}_{\mathrm{i}}\right)$ and their ionized states. In this study, visible bands were strongly observed ranged from 500 to $900 \mathrm{~nm}$. In general, the as-prepared $\mathrm{ZnO}$ had two peaks at 597 $\mathrm{nm}(2.08 \mathrm{eV})$ and $635 \mathrm{~nm}(1.95 \mathrm{eV})$, while for the $\mathrm{ZnO} 400$ sample one peak at $654 \mathrm{~nm}(1.90 \mathrm{eV})$, for the ZnO700 sample: $660 \mathrm{~nm}(1.88 \mathrm{eV})$ and for the $\mathrm{ZnO} 900$ sample: $514 \mathrm{~nm}(2.41 \mathrm{eV})$ and $650 \mathrm{~nm}(1.9$ $\mathrm{eV}$ ) peaks have been observed (Fig. 2). When the annealing temperature increased from $400^{\circ} \mathrm{C}$ to $700^{\circ} \mathrm{C}$, the emission intensity increased. On the contrary, the $900^{\circ} \mathrm{C}$ annealed sample has the lowest visible emission intensity. From these results, it could be concluded that the thermal treatment had a great influence on the types and concentration of defects in $\mathrm{ZnO}$ nanostructures. Annealing process in the air could absorb oxygen on the surface of $\mathrm{ZnO}$ and brought $\mathrm{ZnO}$ into O-rich condition. Janotti et al.[5] suggested that zinc vacancies which act as deep acceptors can more easily form in $n$-type samples, due to its low formation energy, and particularly favorable in oxygen-rich conditions. In 
addition, excess oxygen atoms from air could be accommodated in the form of oxygen interstitial. Thus, contents of oxygen-related defects in annealed samples such as oxygen interstitial, and oxygen vacancy would be increased through thermal treatment at high temperature. The thermodynamic transition for native defects in $\mathrm{ZnO}$ based on Janotti calculation was shown in Figure 3.

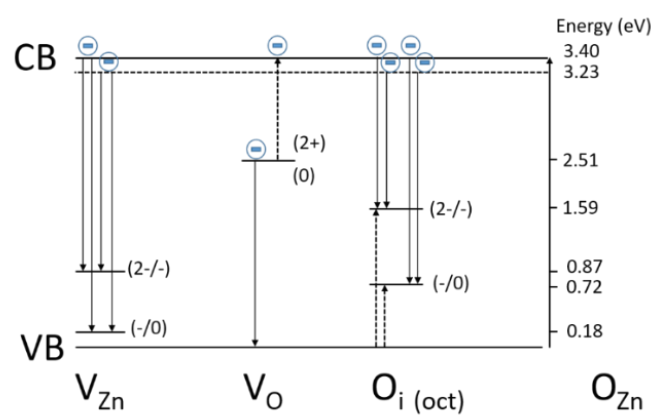

Figure 3. Transition levels for intrinsic defects in $\mathrm{ZnO}$ [5].

To further investigate the intrinsic defects in synthetic $\mathrm{ZnO}$ samples by hydrothermal method and treated at different temperatures, Gaussian-resolved method was used for the visible bands in the PL spectrum. Results were shown in Figure 4.
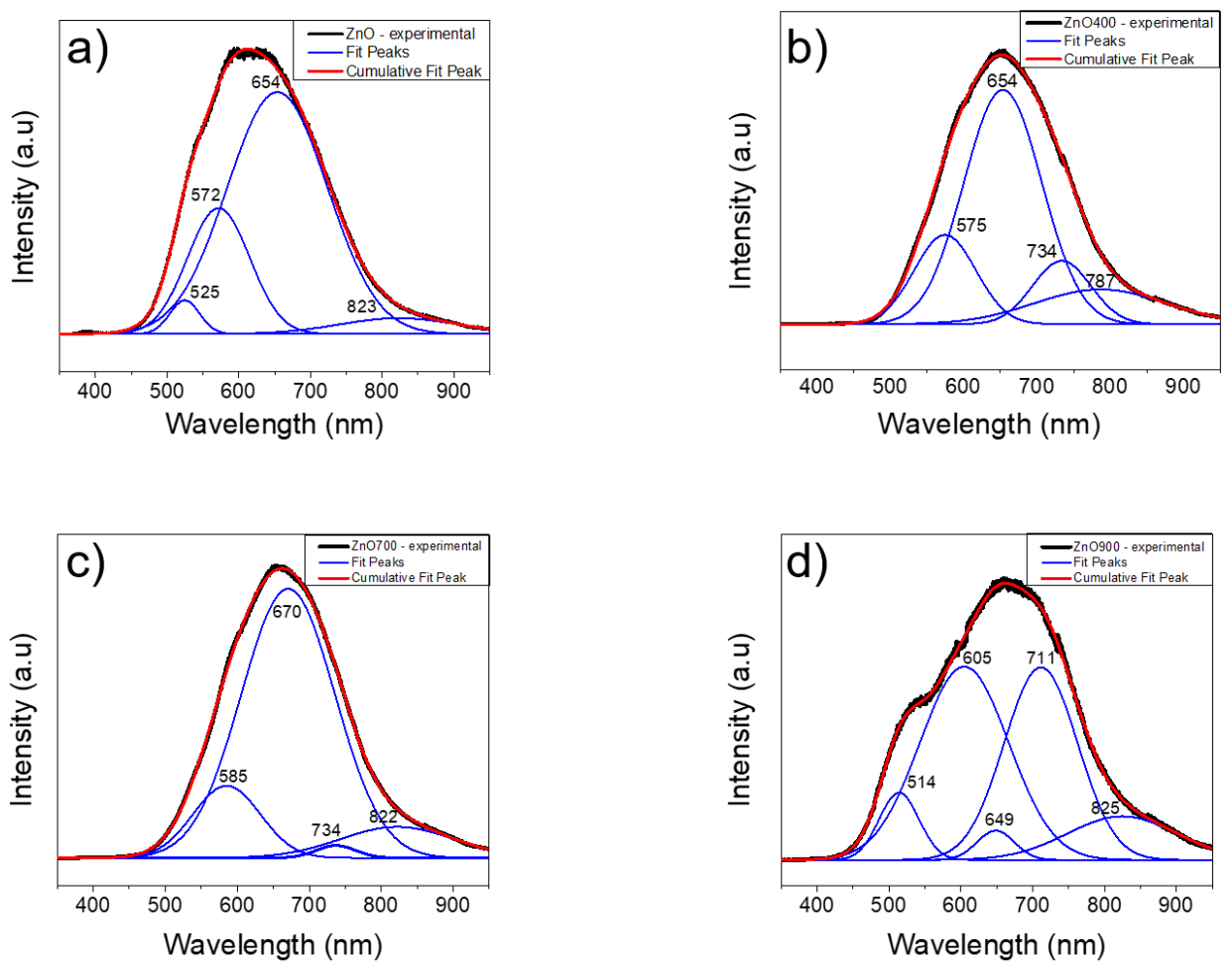

Figure 4. Photoluminescence spectra of: a) $\mathrm{ZnO}$, b) $\mathrm{ZnO} 400$, c) $\mathrm{ZnO} 700$ and d) $\mathrm{ZnO} 900$. 
Firstly, the green emission was observed in deep-level (DL) region at $525 \mathrm{~nm}(2.36 \mathrm{eV})$ and 514 $\mathrm{nm}(2.41 \mathrm{eV})$, respectively, in samples $\mathrm{ZnO}$ and $\mathrm{ZnO} 900$ (Fig. 4a and d). According to studies by Vanheusden [6,7], the correlation between the intensity of the green luminescence and the concentration of $\mathrm{V}_{\mathrm{O}}$ based on the observation of a line with $g \sim 1.96$ in EPR measurement proposed for this emission. In addition, Leiter [8,9] reported the green band around $2.45 \mathrm{eV}$ with oxygen vacancies based on optically detected magnetic resonance experiments. Still, in the debate, Reynolds [10] and Kohan [11] have suggested that transition between the conduction band (or shallow donor) and the $\mathrm{V}_{\mathrm{Zn}}$ are the sources of green band. Based on Janotti's calculation [5], this transition would give rise to luminescence at around $2.4-2.5 \mathrm{eV}$. Moreover, a strong argument in favor of zinc vacancies had been provided by strong passivation of the green emission by hydrogen plasma treatment in experiments of Sekiguchi [12] and Lavrov [13] who simultaneously observed an increase in vibrational modes associated with hydrogenated zinc vacancies. Hydrogen atoms as a donor passivated zinc vacancies which were reported as deep acceptors by forming $\mathrm{O}-\mathrm{H}$ chemical bonds [13]. Secondly, due to the precursors ratio of $\mathrm{Zn}^{2+}: \mathrm{OH}^{-}=1: 10, \mathrm{ZnO}$ itself was in the oxygen-rich condition and then, the annealing in air also may inject additional oxygen into the $\mathrm{ZnO}$ lattice. Thus, defects as excess oxygen $[14,15], \mathrm{O}_{\mathrm{i}}[16]$ or other complex defects $[15,17]$ were attributed to the yellow-orange emissions which were appeared in all samples and red-shifted with increasing the annealing temperature, i.e. $572 \mathrm{~nm}(2.17 \mathrm{eV}), 575 \mathrm{~nm}(2.16 \mathrm{eV}), 585 \mathrm{~nm}(2.12 \mathrm{eV})$ and $605 \mathrm{~nm}(2.05$ $\mathrm{eV}$ ) in $\mathrm{ZnO}, \mathrm{ZnO} 400, \mathrm{ZnO} 700$ and $\mathrm{ZnO} 900$ respectively. Furthermore, the dominant emission peaks appeared in $\mathrm{ZnO}$ samples were in the red region at $654 \mathrm{~nm}(1.90 \mathrm{eV})$ in $\mathrm{ZnO}$ and $\mathrm{ZnO} 400,670 \mathrm{~nm}$ $(1.85 \mathrm{eV})$ in $\mathrm{ZnO} 700$ would possibly be attributed to $\mathrm{O}_{\mathrm{i}(\mathrm{oct})^{2-}}$ defect [5]. Thirdly, the radiative recombination of shallow donor with deep acceptor $\mathrm{O}_{\mathrm{i}}$ could give rise to the NIR luminescence at 734 $\mathrm{nm}(1.69 \mathrm{eV})$ in $\mathrm{ZnO} 400$ and $\mathrm{ZnO} 700,711 \mathrm{~nm}(1.74 \mathrm{eV})$ in $\mathrm{ZnO} 900$ [18]. In this study, we also obtained an infrared emission. This peak occurs in as-prepared $\mathrm{ZnO}$ and $\mathrm{ZnO}$ treated at relatively high temperatures $(\mathrm{ZnO} 700, \mathrm{ZnO} 000)$. We assumed that this emission might be assigned to $\mathrm{O}_{\mathrm{i}}$ (oct). However, yellow - orange, red and other emissions appeared at shorter wavelength region are required further investigation.

Table 1. Summarized percentages of the PL spectra of $\mathrm{ZnO}$ nanostructures annealed at different temperatures de-convoluted by Gaussian distribution.

\begin{tabular}{|c|c|c|c|c|c|}
\hline \multicolumn{6}{|c|}{ Portion of defect contribution (\%) } \\
\hline Emission (nm) & Origin & As-prepared $\mathrm{ZnO}$ & $\mathrm{ZnO400}$ & $\mathrm{ZnO700}$ & $\mathrm{ZnO900}$ \\
\hline Green & $\mathrm{V}_{\mathrm{Zn}}[5],[11],[10]$ & 2.91 & & & 6.89 \\
\hline $495-570$ & & $525 \mathrm{~nm}$ & & & $514 \mathrm{~nm}$ \\
\hline Yellow - Orange & Excess oxygen[14],[15], & 22.71 & 17.59 & 14.52 & 44.22 \\
\hline $570-620$ & $\begin{array}{l}\mathrm{O}_{\mathrm{i}}[16] \text { or other complex } \\
\text { defects[17],[15] }\end{array}$ & $572 \mathrm{~nm}$ & $575 \mathrm{~nm}$ & $585 \mathrm{~nm}$ & $605 \mathrm{~nm}$ \\
\hline Red & $\mathrm{O}_{\mathrm{i}(\mathrm{oct})^{2-}} \operatorname{defect}[5]$ & 70.25 & 58.32 & 75.79 & 2.81 \\
\hline $620-750$ & & $654 \mathrm{~nm}$ & $654 \mathrm{~nm}$ & $670 \mathrm{~nm}$ & $649 \mathrm{~nm}$ \\
\hline NIR & $\begin{array}{l}\text { Radiative recombination } \\
\text { of shallow donor with } \\
\left.\text { deep acceptor } \mathrm{O}_{\mathrm{i}[} 18\right]\end{array}$ & & $\begin{array}{l}11.85 \\
734 \mathrm{~nm}\end{array}$ & $\begin{array}{l}1.46 \\
734 \mathrm{~nm}\end{array}$ & $\begin{array}{l}36.49 \\
711 \mathrm{~nm}\end{array}$ \\
\hline Infrared emission & $\mathrm{O}_{\mathrm{i}(\mathrm{oct})^{-}}[5]$ & $\begin{array}{l}4.01 \\
823 \mathrm{~nm}\end{array}$ & $\begin{array}{l}12.52 \\
787 \mathrm{~nm}\end{array}$ & $\begin{array}{l}8.18 \\
822 \mathrm{~nm}\end{array}$ & $\begin{array}{l}9.65 \\
825 \mathrm{~nm}\end{array}$ \\
\hline
\end{tabular}




\subsection{Photocatalytic activity}

Photocatalytic activities of hydrothermal $\mathrm{ZnO}$ samples were evaluated by the degradation of Methylene blue (MB, $\geq 99 \%$, Jinhuada) $\mathrm{C}_{16} \mathrm{H}_{18} \mathrm{CIN}_{3} \mathrm{~S} .3 \mathrm{H}_{2} \mathrm{O}\left(\mathrm{M}=373.90\right.$ g.mol $\left.{ }^{-1}\right)$, a redox indicator used in chemical analysis, which has the most dominant peak at $664 \mathrm{~nm}$. This solution is discolored in the redox environment. Hence, $\mathrm{MB}$ is often used to evaluate the photocatalytic ability of materials. The measurement process was as followed. Firstly, MB was dissolved in $1 \mathrm{~L}$ of distilled water stored in a $1500 \mathrm{~mL}$ volumetric flask in a dark room to obtain a concentration $\mathrm{C}=25.10^{-6}\left(\mathrm{~mol}^{\mathrm{L}} \mathrm{L}^{-1}\right)$. Then, 20 $\mathrm{mg}$ of $\mathrm{ZnO}$ materials were added in $250 \mathrm{~mL} \mathrm{MB}$ solution under vigorous stirring for 60 mins in dark at room temperature to get adsorption equilibrium. Finally, the solution was under direct sunlight irradiation and UV-Vis absorption measurement (DR 5000) was recorded after every $30 \mathrm{~min}$ of irradiation until $150 \mathrm{~min}$. The photocatalytic efficiency for MB degradation could be calculated as [19]:

$$
\eta(\%)=\left(1-\frac{C}{C_{0}}\right) \times 100 \%
$$

where $\mathrm{C}_{0}$ is the $\mathrm{MB}$ initial absorption value, and $\mathrm{C}$ is the $\mathrm{MB}$ absorption value at each time of measurement.

The absorption spectra of $\mathrm{ZnO} 400$ and $\mathrm{ZnO} 700$ were shown in Fig. 5. As one can see, the photocatalytic activity of $\mathrm{ZnO}$ improves when $\mathrm{ZnO}$ was annealed at $700^{\circ} \mathrm{C}$. Fig. 6 showed the $\mathrm{MB}$ degradation at the most dominant peak $(664 \mathrm{~nm})$. After $150 \mathrm{~min}$, the photocatalytic efficiencies of $\mathrm{ZnO}, \mathrm{ZnO} 400$, and $\mathrm{ZnO} 700$ were $21 \%, 48 \%$, and $79 \%$, respectively. Then the thermal annealing has a great effect on photocatalytic activity of $\mathrm{ZnO}$. When increasing the annealing temperature of $\mathrm{ZnO}$ until $700^{\circ} \mathrm{C}$, the PL intensity was increased routinely. Thus, the interaction of excited electrons in the environment was increased in the sample with higher annealed temperature which could be a reason to enhance the photocatalytic activity.
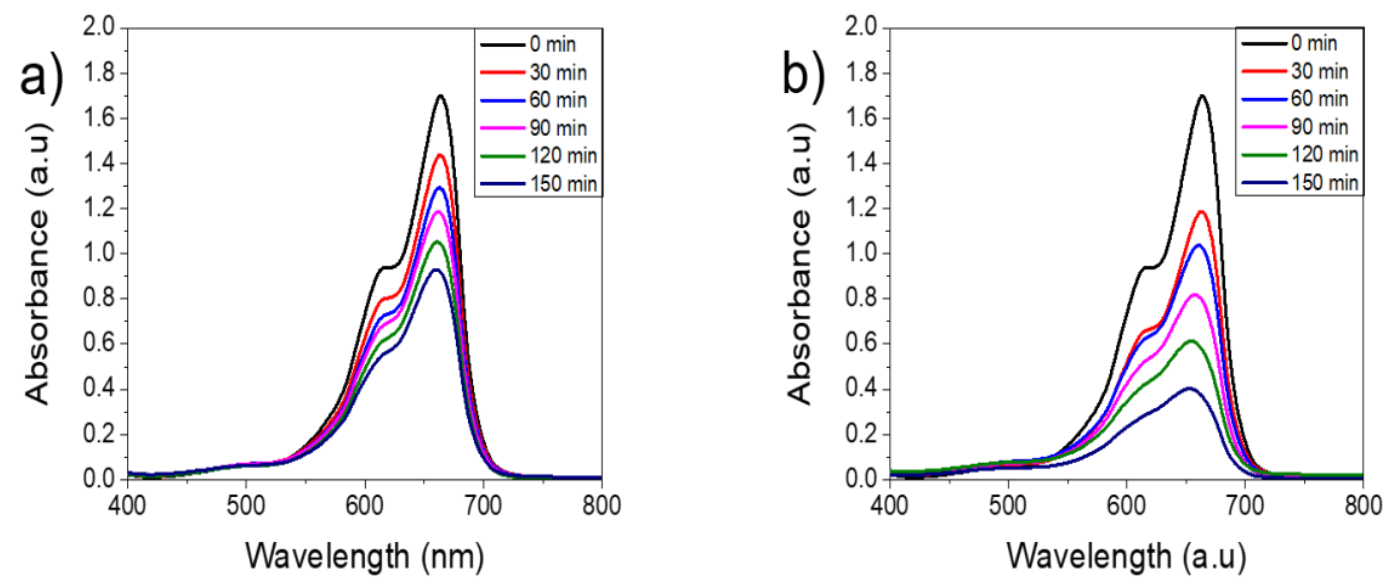

Figure 5. The schematic of the adsorption, photocatalytic activities of $\mathrm{ZnO} 400$ and $\mathrm{ZnO} 700$ prepared by hydrothermal method and examined for $150 \mathrm{~min}$ with $\mathrm{MB}$ as the color indicator: a) $\mathrm{ZnO} 400$ and b) $\mathrm{ZnO} 700$. 


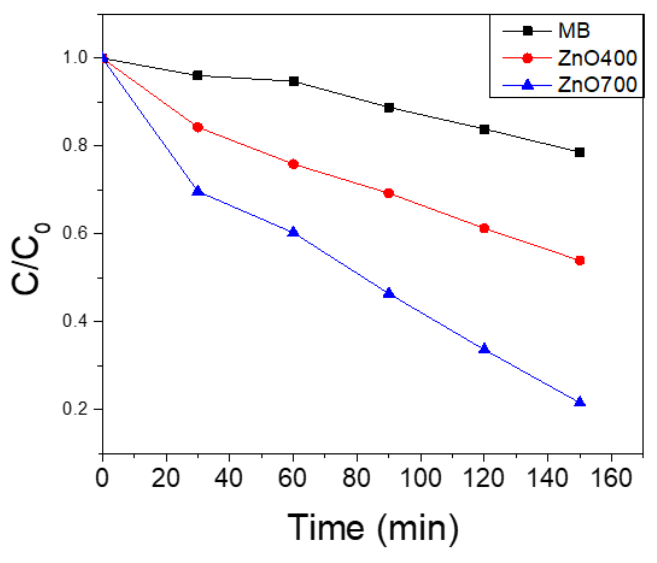

Figure 6. Methylene blue degradation at $664 \mathrm{~nm}$ under sunlight irradiation of $\mathrm{ZnO}(\mathrm{MB}), \mathrm{ZnO} 400$, and $\mathrm{ZnO} 700$.

\section{Conclusions}

In this study, homogeneous wurtzite $\mathrm{ZnO}$ nanorods were synthesized by a facile hydrothermal method. The resulted sample was annealed in air at different temperatures 400,700 , and $900^{\circ} \mathrm{C}$. The photoluminescence emission spectra of these samples showed that the intensity of the visible-range emission was increased with the temperature increased until $700^{\circ} \mathrm{C}$. The PL line shape of these samples was similar to each other indicating that they have the same emission origin. However, the deconvolution of PL emissions showed that the proportions of emission peaks were different. The photocatalytic activities of the samples in the degradation of MB solution have been evaluated and this showed that the higher intensity of PL emission gave better photocatalytic activity.

\section{Acknowledgements}

This research is funded by Vietnam National Foundation for Science and Technology Development (NAFOSTED) under Grant Number 103.02-2016.87

\section{References}

[1] F. Achouri, S. Corbel, L. Balan, K. Mozet, E. Girot, G. Medjahdi, M.B. Said, A. Ghrabi, R. Schneider, Porous Mn-doped $\mathrm{ZnO}$ nanoparticles for enhanced solar and visible light photocatalysis, Mater. Des., 101 (2016) 309316. https://doi.org/10.1016/j.matdes.2016.04.015

[2] S. Choi, J.Y. Do, J.H. Lee, C.S. Ra, S.K. Kim, M. Kang, Optical properties of Cu-incorporated ZnO (Cu x Zn y O) nanoparticles and their photocatalytic hydrogen production performances, Mater. Chem. Phys., 205 (2018) 206-209.

https://doi.org/10.1016/j.matchemphys.2017.11.022

[3] X.M. Fan, J.S. Lian, L. Zhao, Y.H. Liu, Single violet luminescence emitted from ZnO films obtained by oxidation of Zn film on quartz glass, Appl. Sur. Sci., 252 (2005) 420-424.

https://doi.org/10.1016/j.apsusc.2005.01.018 
[4] C.T. Quy, N.X. Thai, N.D. Hoa, D.T.T. Le, C.M. Hung, N.V. Duy, N.V. Hieu, $\mathrm{C}_{2} \mathrm{H}_{5} \mathrm{OH}$ and $\mathrm{NO}_{2}$ sensing properties of $\mathrm{ZnO}$ nanostructures: correlation between crystal size, defect level and sensing performance, RSC Adv., 8 (2018) 5629-5639. https://doi.org/10.1039/C7RA13702H

[5] A. Janotti, C.G. van de Walle, Native point defects in ZnO, Phys. Rev. B, 76 (2007) 165202. https://doi.org/10.1103/PhysRevB.76.165202

[6] K. Vanheusden, C.H. Seager, W.L. Warren, D.R. Tallant, J.A. Voigt, Correlation between photoluminescence and oxygen vacancies in $\mathrm{ZnO}$ phosphors, Appl. Phys. Lett., 68 (1996) 403. https://doi.org/10.1063/1.116699

[7] K. Vanheusden, C. H. Seager, W.L. Warren, D.R. Tallant, J. Caruso, M.J. Hampden-Smith, T.T. Kodas, Green photoluminescence efficiency and free-carrier density in $\mathrm{ZnO}$ phosphor powders prepared by spray pyrolysis, J. Lumin., 75 (1997) 11-16. https://doi.org/10.1016/S0022-2313(96)00096-8

[8] F.H. Leiter, H.R. Alves, A. Hofstaetter, D.M. Hofmann, B.K. Meyer, The Oxygen Vacancy as the Origin of a Green Emission in Undoped ZnO, Phys. Status Solidi (b), 226 (2001) R4-R5. https://doi.org/10.1002/1521-3951(200107)226:1<R4::AID-PSSB99994>3.0.CO;2-F

[9] F. Leiter, H. Alves, D. Pfisterer, N.G. Romanov, D.M. Hofmann, B.K. Meyera, Oxygen vacancies in ZnO, Physica B: Condens. Matter, 340-342 (2003) 201-204. https://doi.org/10.1016/j.physb.2003.09.031

[10] D.C. Reynolds, D.C. Look, B. Jogai, J.E. Van Nostrand, R. Jonesb, J. Jennyb, Source of the yellow luminescence band in GaN grown by gas-source molecular beam epitaxy and the green luminescence band in single crystal ZnO, Solid State Commun., 106 (1998) 701-704. https://doi.org/10.1016/S0038-1098(98)00048-9

[11] A.F. Kohan, G. Ceder, D. Morgan, C.G. Van de Walle, First-principles study of native point defects in ZnO, Phys. Rev. B, 61 (2000) 15019. https://doi.org/10.1063/1.3089232

[12] T. Sekiguchi, N. Ohashi, Y. Terada, Effect of Hydrogenation on ZnO Luminescence, Jpn. J. Appl. Phys., 36 (1997) 289-291. https://doi.org/10.1143/JJAP.36.L289

[13] E.V. Lavrov, J. Weber, F. Börrnert, Chris G. Van de Walle, R. Helbig, Hydrogen-related defects in ZnO studied by infrared absorption spectroscopy, Phys. Rev. B, 66 (2002) 165205. https://doi.org/10.1103/PhysRevB.66.165205

[14] Y.Y. Tay, T.T. Tan, F. Boey, M.H. Liang, J. Ye, Y. Zhao, T. Norby, S. Li, Correlation between the characteristic green emissions and specific defects of ZnO, Phys. Chem. Chem. Phys., 12 (2010) 2373-2379 https://doi.org/10.1039/b922372j

[15] M. S. Ramanachalam, A. Rohatgi, W. B. Carter, J. P. Schaffer, T. K. Gupta, Photoluminescence study of ZnO varistor stability, J. Electron. Mater., 24 (1995) 413-419. https://doi.org/10.1007/BF02659707

[16] M. Willander, O. Nur, J.R. Sadaf, M.I. Qadir, S. Zaman, A. Zainelabdin, N. Bano, I. Hussain, Luminescence from Zinc Oxide Nanostructures and Polymers and their Hybrid Devices, Materials, 3 (2010) 2643-2667. https://doi.org/10.3390/ma3042643

[17] A.B. Djurisic, X.Y. Chen, H.Y. Leung, Recent Progress in Hydrothermal Synthesis of Zinc Oxide Nanomaterials, Recent Pat. Nanotechnol., 6 (2012) 124-134(111). https://doi.org/10.2174/187221012800270180

[18] M. Wang, Y. Zhou, Y. Zhang, E.J. Kim, S.H. Hahn, S.G. Seong, Near-infrared Photoluminescence from ZnO, Appl. Phys. Lett., 100 (2012) 101906. https://doi.org/10.1063/1.3692584

[19] N.X. Sang, P.T.L. Huong, T.T.M. Thy, P.T. Dat, V.C. Minh, N.H. Tho, Crystalline deformation and photoluminescence of titanium dioxide nanotubes during in situ hybridization with graphene: An example of the heterogeneous photocatalyst, Superlattice. Microst., 121 (2018) 9-15. https://doi.org/10.1016/j.spmi.2018.07.020 